\title{
OPEN Clinicopathological and Prognostic Role of STAT3/p-STAT3 in Breast Cancer Patients in China: A Meta- \\ Analysis
}

Received: 1 May 2018

Accepted: 17 July 2019

Published online: 02 August 2019
Yang $\mathrm{Li}^{2}$, Yue Wang ${ }^{6}$, Zhixiang Shi ${ }^{5}$, Jinghan Liu ${ }^{3}$, Shuyun Zheng ${ }^{4}$, Jinsong Yang ${ }^{4}$, Yi Liu ${ }^{5}$, Yuhua Yang ${ }^{7}$, Feng Chang ${ }^{2}$ \& Wenying Yu ${ }^{1}$

In order to explore the important factors in the diagnosis of breast cancer in China, meta-analysis of previous studies was performed to understand the association between STAT3/p-STAT3 and breast cancer. Information about STAT3/p-STAT3 expression and clinical data about breast cancer in China in particular were gathered from PubMed, Web of Science, CNKI and WanFang databases. RevMan 5.3 and STATA 14.0 were used to analyze the occurrence, development and metastasis of breast cancer for 2818 patients in 18 studies. STAT3/p-STAT3 expression was higher in breast cancer tissue than in normal ones $(\mathrm{OR}=7.48,95 \% \mathrm{Cl}=5.64-9.94)$, in highly differentiated breast cancer tissue than in lowly differentiated cancer tissues $(\mathrm{OR}=2.13,95 \% \mathrm{Cl}=1.53-2.98)$, in III/IV stage breast cancer than in I/II stage breast cancer $(\mathrm{OR}=3.58,95 \% \mathrm{Cl}=2.44-5.25)$, and in tissue with lymphatic metastasis than in normal tissues $(\mathrm{OR}=3.72,95 \% \mathrm{Cl}=2.59-5.35)$, respectively. Thus, the expression of STAT3/p-STAT3 plays a clinicopathological and prognostic role in the diagnosis and treatment of Chinese breast cancer patients.

Breast cancer remains to be the leading cause of death for women in China. Though the incidence of breast cancer is the highest among all cancers, its early diagnosis is still undesirable ${ }^{1}$. Therefore, it is very necessary to explore the important factors in the diagnosis of breast cancer. Controversial evidence of the relationship between the expression of signal transducer and activator of transcription proteins 3 (STAT3) and breast cancer as a clinicopathologic and prognostic factor in Chinese women has been observed ${ }^{2}$.

STAT3 is a latent cytosolic transcription factor and activates genes in human chromosome 12(q13 to q14-1) by phosphorylation of tyrosine705 in the SH2 domain ${ }^{3}$. Over-activated STAT3 plays an important role in multiple malignant cases, especially in breast cancer ${ }^{4}$. Phosphorylated STAT3 (p-STAT3) dimerizes spontaneously, migrates into cell nucleus and activates the expression of downstream genes to regulate the tumor cell growth, proliferation, differentiation and metastasis ${ }^{5}$. In addition, activated STAT3 was reported to affect the resistance of anti-breast cancer drugs like Paclitaxel ${ }^{6}$ and Adriamycin ${ }^{7}$.

In recent years, due to the complex pathophysiology and various influencing factors, breast cancer, which is usually difficult to be diagnosed and remedied, has become the top lethal cancer for Chinese women ${ }^{8,9}$. A higher STAT3/p-STAT3 expression level was observed in breast cancer tissue than in normal tissues, which aroused our interest to study the relationships between STAT3/p-STAT3 expression level and the occurrence, development and metastasis of breast cancer in Chinese women.

\footnotetext{
${ }^{1}$ State Key Laboratory of Natural Medicines, China Pharmaceutical University, Nanjing, 211198, P. R. China. ${ }^{2}$ School of International Pharmaceutical Business, China Pharmaceutical University, Nanjing, 211198, P. R. China. ${ }^{3}$ School of Life Science and Technology, China Pharmaceutical University, Nanjing, 211198, P. R. China. ${ }^{4}$ Nanjing First Hospital, China Pharmaceutical University, Nanjing, 211198, P. R. China. ${ }^{5}$ Foreign Languages Department, China Pharmaceutical University, Nanjing, 211198, P. R. China. ${ }^{6}$ School of Pharmacy, Guangxi Medical University, Nanning, 530021, P. R. China. ${ }^{7}$ The Department of Dermatology, The First People's Hospital of Changzhou, Changzhou, 213003, P. R. China. Correspondence and requests for materials should be addressed to F.C. (email: cfcpu72@163. com) orW.Y. (email: ywy@cpu.edu.cn)
} 


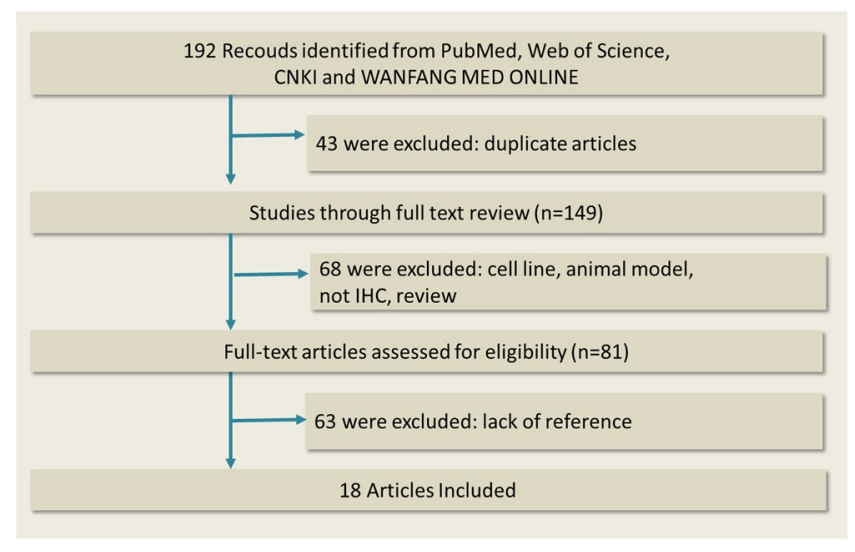

Figure 1. Flow chart of literature search.

Meta-analysis was used to assess and evaluate the literature reporting the correlations between STAT3/p-STAT3 and breast cancer, with an attempt to decrease the bias of literature and to provide new therapeutic strategy to Chinese women's breast cancer.

\section{Materials and Methods}

Search strategy. PubMed, Web of Science, CNKI and WanFang were used to search for papers concerned, which were published before March 2019. Terms in the searching strategy like "breast cancer", "breast tumor", "STAT3 ", "Signal transducer and activator of transcription 3", "p-STAT3" and "phospho-STAT3" were used. The flow chart of the literature search is shown in Fig. 1 as follows.

Inclusion criteria. (1) Studies are from journal articles; (2) Normal breast tissue or breast benign hyperplasia as a control group was provided; (3) Immunohistochemistry (IHC) must be used in the studies to detect the expression level of STAT3 and p-STAT3 in the breast carcinoma and non-carcinomatous tissue; (4) The research materials in the studies should be from hospitals.

Exclusion criteria. (1) Literatures published as letters, reviews or meeting reports; (2) Articles without a contrast with non-carcinomatous tissue; (3) The research materials collected from breast carcinoma cell lines or animal tumor model; (4) Incomplete data.

Screen and Excerpt. All studies were brought into this research by two researchers independently according to the exclusion and inclusion criteria, with the full text being acquired with the extracted data inside. After all the data were crosschecked, divergence would be discussed and the third researcher would give some references. The extracted data included characteristic data, the focused type, numbers of treatment and control groups and the expression level of STAT3 or p-STAT3 in treatment and control groups, age groups, tissue types, TNM stages, tumor sizes and the states of lymphatic metastasis.

Quality assessment. Quality assessment was performed by two researchers separately, with differences being resolved through discussion. We referred to the Cochrane evaluation clauses: (1) Random sequence generation; (2) Allocation concealment; (3) Blind method; (4) Incomplete outcome data; (5) Non-selective ending report; (6) Without other bias source. Each coincident item gives one point. Studies with scores $\geq 3$ were assigned as high-quality studies.

Statistical analysis. Extracted data were used to analyze the correlation between the expression of STAT3 or p-STAT3 and the focused type, the numbers of treatment and control groups, the expression level of STAT3 or p-STAT3 in treatment and control groups, age groups, tissue types, TNM stages, tumor sizes and the states of lymphatic metastasis. All data in literatures were combined to obtain a value of OR (Odds Ratio) and 95\% CI (Confidential Interval). For the results of $\chi^{2}$ test, when $\mathrm{P}<0.1$ and $\mathrm{I}^{2}>50 \%$, supra presence included significant heterogeneity, using the random effects model by choosing the model option in the Review Manager 5.3 software when generating the forest plots. Then, regression was analyzed by drawing funnel plot and Egger's test. The analysis was performed using STATA statistical software version 14.0.

\section{Results}

Essential characteristics and quality evaluation. According to the inclusion and exclusion criteria, 2818 tissue samples of 18 research studies were chosen and analyzed. Among them, 1672 cases (1188 breast cancer tissues and 484 normal tissues) of 9 studies focused on expression level of p-STAT3 while 1445 cases (870 breast cancer tissues and 575 normal tissues) of 12 studies focused on expression level of STAT3, as shown in Table 1. Yang Z and Ying MZ's studies contained both STAT3 and p-STAT3.

Results from the 18 research studies: 13 studies reported the correlation of expression level and breast cancer occurrence ( 6 on p-STAT3 and 7 on STAT3, with Yang Z and Ying MZ's studies containing both STAT3 and p-STAT3); 13 studies reported the correlation of STAT3 expression level and histological differentiation (5 on 


\begin{tabular}{|l|l|l|l|l|l|l|l|}
\hline No. & First author & Year & Type of study & Control group & Experiment group & Score & PA \\
\hline 1 & Chen TT $^{35}$ & 2012 & Case control test & 36 & 160 & 4 & Santa Cruz, USA \\
\hline 2 & Fang $\mathrm{M}^{36}$ & 2014 & Case control test & 48 & 33 & 4 & ab15523, Abcam, UK \\
\hline 3 & Guo W $^{37}$ & 2009 & Case control test & 30 & 76 & 3 & MXB, PRC \\
\hline 4 & Li SJ $^{38}$ & 2011 & Case control test & 25 & 42 & 4 & Abcam, UK \\
\hline 5 & Ma JW $^{39}$ & 2012 & Case control test & 40 & 84 & 4 & ZSGB, PRC \\
\hline 6 & Qi F $^{40}$ & 2010 & Case control test & 30 & 80 & 3 & MXB, PRC \\
\hline 7 & Zhang N $^{41}$ & 2016 & Case control test & 24 & 355 & 3 & NR \\
\hline 8 & Wang J & 2015 & Case control test & 245 & 379 & 4 & Abcam, USA \\
\hline 9 & Zhou T & 2013 & Case control test & 15 & 93 & 3 & sc-99086, CA \\
\hline 10 & Xu S & 2016 & Case control test & 160 & 80 & 4 & Santa Cruz, USA \\
\hline 11 & Yang J & 2012 & Case control test & 26 & 126 & 4 & BA0621, BOSTER, PRC \\
\hline 12 & Yang Z & 2011 & Case control test & 10 & 36 & 4 & MXB, PRC \\
\hline 13 & Ying $\mathrm{MZ}^{47}$ & 2007 & Case control test & 41 & 71 & 4 & Upstate, USA \\
\hline 14 & Yue XC & 2009 & Case control test & 25 & 51 & 5 & ZSGB, PRC \\
\hline 15 & Zhang W & 2008 & Case control test & 12 & 45 & 4 & CST, USA \\
\hline 16 & Wang QT & 2017 & Case control test & 73 & 57 & 4 & BS1141R, CHN \\
\hline 17 & Tan $\mathrm{QF}^{51}$ & 2017 & Case control test & 41 & 19 & 5 & Santa Cruz, USA \\
\hline 18 & Chen $\mathrm{TT}^{52}$ & 2016 & Case control test & 50 & 100 & 4 & Santa Cruz, USA \\
\hline
\end{tabular}

Table 1. Essential characteristics and quality evaluation in the research. PA, primary antibody used for IHC; The score is based on cochrane risk of bias tool: 1 : adequate sequence generation; 2: allocation concealment; 3 : blinding; 4: incomplete outcome data address; 5 : free of selective reporting; 6 : free of other source of bias.

\begin{tabular}{|c|c|c|c|c|c|c|c|c|c|c|c|c|c|c|c|c|c|}
\hline \multirow{4}{*}{\begin{tabular}{|l|} 
No. \\
1 \\
2
\end{tabular}} & \multirow{3}{*}{\begin{tabular}{|l|}
$\begin{array}{l}\text { First } \\
\text { author }\end{array}$ \\
Chen TT \\
\end{tabular}} & \multirow{3}{*}{\begin{tabular}{|l|} 
Year \\
2012
\end{tabular}} & \multirow{3}{*}{\begin{tabular}{|l|} 
Type \\
p-STAT3 \\
\end{tabular}} & & & & \multicolumn{2}{|c|}{$\begin{array}{l}\text { Lymph node } \\
\text { metastasis (+/-) }\end{array}$} & \multicolumn{3}{|c|}{ Histological grades $(+/-)$} & \multicolumn{4}{|c|}{ TNM phases $(+/-)$} & \multicolumn{2}{|c|}{$\begin{array}{l}\text { Tumor sizes }(\mathrm{cm}) \\
(+/-)\end{array}$} \\
\hline & & & & \multicolumn{3}{|l|}{ Age (+/-) } & Positive & Negative & 1 & 2 & 3 & 1 & 2 & 3 & 4 & $\leq 2:$ & $>2:$ \\
\hline & & & & $\leq 35: 13 / 3$ & $35-55: 62 / 30$ & $>55: 36 / 16$ & NR & NR & $8 / 5$ & $69 / 33$ & $34 / 11$ & \multicolumn{2}{|l|}{$47 / 39$} & \multicolumn{2}{|l|}{$64 / 10$} & $2 / 11$ & $109 / 38$ \\
\hline & Fang M & 2014 & STAT3 & $\leq 50: 18 / 0$ & $>50: 14 / 1$ & NR & NR & NR & $9 / 0$ & $12 / 1$ & $11 / 0$ & $8 / 0$ & $14 / 1$ & $4 / 0$ & $4 / 0$ & NR & NR \\
\hline 3 & Guo $W$ & 2009 & STAT3 & $\leq 50: 26 / 9$ & $>50: 24 / 17$ & NR & $32 / 10$ & $18 / 16$ & \multicolumn{2}{|l|}{$23 / 19$} & $27 / 7$ & \multicolumn{2}{|l|}{$30 / 22$} & \multicolumn{2}{|l|}{$20 / 4$} & $17 / 10$ & $33 / 16$ \\
\hline 4 & Li SJ & 2011 & STAT3 & $\leq 50: 20 / 17$ & $>50: 22 / 8$ & NR & $32 / 11$ & $10 / 14$ & NR & NR & NR & $5 / 7$ & $18 / 14$ & $19 / 4$ & NR & $17 / 7$ & $25 / 18$ \\
\hline 5 & Ma JW & 2012 & p-STAT3 & NR & NR & NR & $32 / 14$ & $20 / 18$ & \multicolumn{2}{|l|}{$23 / 22$} & $30 / 9$ & \multicolumn{2}{|l|}{$32 / 23$} & \multicolumn{2}{|l|}{$22 / 6$} & NR & NR \\
\hline 6 & Qi FJ & 2010 & STAT3 & NR & NR & NR & $34 / 10$ & $18 / 18$ & \multicolumn{2}{|l|}{$23 / 20$} & $29 / 8$ & \multicolumn{2}{|l|}{$31 / 23$} & \multicolumn{2}{|l|}{$21 / 5$} & NR & NR \\
\hline 7 & \begin{tabular}{|l|} 
Zhang N \\
\end{tabular} & 2016 & p-STAT3 & NR & NR & NR & $159 / 8$ & $196 / 16$ & NR & NR & NR & \multicolumn{2}{|c|}{$292 / 20$} & \multicolumn{2}{|l|}{$63 / 4$} & 109/113 & $246 / 266$ \\
\hline 8 & Wang J & 2015 & p-STAT3 & NR & NR & NR & $159 / 8$ & $196 / 16$ & NR & NR & NR & \multicolumn{2}{|c|}{$292 / 20$} & \multicolumn{2}{|l|}{$63 / 4$} & $109 / 4$ & $246 / 20$ \\
\hline 9 & Zhou T & 2013 & STAT3 & $\leq 50: 43 / 4$ & 50:50/11 & NR & $64 / 4$ & $21 / 11$ & $21 / 3$ & $42 / 6$ & $30 / 6$ & NR & NR & NR & NR & NR & NR \\
\hline 10 & Xu S & 2016 & STAT3 & NR & NR & NR & $21 / 12$ & $31 / 16$ & $3 / 1$ & $31 / 11$ & $18 / 16$ & NR & NR & NR & NR & NR & NR \\
\hline 11 & Yang J & 2012 & STAT3 & $<50: 50 / 12$ & $\geq 50: 48 / 16$ & NR & $76 / 8$ & $28 / 14$ & $10 / 2$ & $58 / 14$ & $36 / 6$ & NR & NR & NR & NR & NR & NR \\
\hline \multirow[t]{2}{*}{12} & Yang Z & 2011 & STAT3 & $\leq 50: 10 / 7$ & $>50: 11 / 8$ & NR & $12 / 3$ & $9 / 12$ & NR & NR & NR & \multicolumn{2}{|l|}{$11 / 13$} & \multicolumn{2}{|l|}{$10 / 2$} & $6 / 7$ & $15 / 8$ \\
\hline & & & p-STAT3 & $\leq 50: 9 / 8$ & $>50: 11 / 8$ & NR & $13 / 2$ & $7 / 14$ & NR & NR & NR & \multicolumn{2}{|l|}{6} & \multicolumn{2}{|l|}{$11 / 1$} & $8 / 5$ & $12 / 11$ \\
\hline 13 & Ying MZ & 2007 & STAT3 & $\leq 40: 11 / 5$ & $41-60: 37 / 8$ & $>60: 8 / 2$ & $31 / 9$ & $25 / 6$ & $5 / 5$ & $22 / 6$ & $29 / 4$ & $6 / 2$ & $22 / 12$ & $24 / 1$ & $4 / 0$ & NR & NR \\
\hline & & & p-STAT3 & $\leq 40: 13 / 3$ & $41-60: 28 / 17$ & $>60: 8 / 2$ & $34 / 6$ & $15 / 16$ & $7 / 3$ & $14 / 14$ & $28 / 5$ & $4 / 4$ & $20 / 14$ & $23 / 2$ & $2 / 2$ & NR & NR \\
\hline 14 & Yue XC & 2009 & STAT3 & $<35: 7 / 1$ & $35-50: 26 / 3$ & $>50: 11 / 3$ & $28 / 1$ & $16 / 6$ & $10 / 3$ & $24 / 2$ & $10 / 2$ & $7 / 1$ & $31 / 5$ & $6 / 1$ & NR & $6 / 4$ & $32 / 1$ \\
\hline 15 & Zhang W & 2008 & p-STAT3 & $<50: 7 / 4$ & $\geq 50: 20 / 14$ & NR & $14 / 4$ & $13 / 14$ & NR & NR & NR & NR & NR & NR & NR & $1 / 3$ & $26 / 15$ \\
\hline 16 & Wang QT & 2017 & STAT3 & $<60$ & $\geq 60$ & NR & $30 / 27$ & $8 / 65$ & $11 / 8$ & $43 / 53$ & $3 / 12$ & $2 / 9$ & $23 / 55$ & $32 / 9$ & NR & & \\
\hline 17 & Tan QF & 2017 & p-STAT3 & NR & NR & NR & NR & NR & $23 / 20$ & & $15 / 2$ & $22 / 21$ & & $16 / 1$ & & $15 / 10$ & $27 / 8$ \\
\hline 18 & Chen TT & 2016 & STAT3 & $\leq 35: 11 / 4$ & $\leq 55: 58 / 29$ & $>55: 31 / 17$ & $76 / 24$ & $22 / 28$ & $7 / 5$ & $61 / 34$ & $32 / 11$ & $43 / 36$ & & $57 / 14$ & & $2 / 10$ & $98 / 40$ \\
\hline
\end{tabular}

Table 2. Characteristics of included studies in the research. NR: No report; p-STAT3: phosphorylated STAT3; TNM: tumour node metastases; + :STAT3/p-STAT3 positive; -:STAT3/p-STAT3 negative.

p-STAT3 and 8 on STAT3, with Ying MZ's study containing both STAT3 and p-STAT3); 15 studies reported the correlation of expression level and breast cancer TNM stages (8 on p-STAT3 and 7 on STAT3, with Yang Z and Ying MZ's studies containing both STAT3 and p-STAT3); 11 studies reported the correlation of expression level and breast cancer lymphatic metastasis (7 on p-STAT3 and 4 on STAT3). The results are shown in Table 2.

The results of STAT3 expression and analysis. Correlation between STAT3/p-STAT3 expression level and breast cancer occurrence. 13 studies reported the correlation between STAT3 expression level and breast cancer occurrence, 6 on p-STAT3 and 7 on STAT3, 1362 cases for breast cancer tissues and 773 for normal tissues. No substantial heterogeneity existed with each group $\left(\mathrm{P}=0.30, \mathrm{I}^{2}=14 \%\right)$, and we performed the meta-analysis 
Study or Subgroup

\subsubsection{STAT3}

Guo W et al.2009

Li SJ et al.2016

Qi FJ et al.2010

Yang $J$ et al.2012

Yang $Z(A)$ et al.2011

Ying MZ(A) et al.200?

Yue XC et al.2009

Subtotal $(95 \% \mathrm{Cl})$

Total events

Heterogeneity: $\mathrm{Tau}^{2}=0.21 ; \mathrm{Chi}^{2}=10.40, \mathrm{df}=6(\mathrm{P}=0.11) ; \mathrm{I}^{2}=42 \%$

Test for owerall effect: $Z=8.02(P<0.00001)$

\subsection{2 p-STAT3}

\begin{tabular}{|c|c|c|}
\hline Chen $\pi$ et al. 2012 & $10.8 \%$ & $4.53[2.10,9.79]$ \\
\hline Ma JW et al.2012 & $9.1 \%$ & $7.08[3.01,16.65]$ \\
\hline Wang $J$ et al.2015 & $20.9 \%$ & $9.05[5.56,14.73]$ \\
\hline Yang $Z$ (B) et al. 2011 & $0.9 \%$ & $26.09[1.42,479.02]$ \\
\hline Ying $M Z(B)$ et al. 2007 & $9.4 \%$ & $5.38[2.32,12.47]$ \\
\hline Zhang W et al. 2008 & $2.9 \%$ & $7.50[1.47,38.32]$ \\
\hline Subtotal $(95 \% \mathrm{Cl})$ & $54.1 \%$ & $7.13[5.13,9.92]$ \\
\hline \multicolumn{3}{|c|}{$\begin{array}{l}\text { Total events } \\
\text { Heterogeneity: } \text { Tau }^{2}=0.00 ; \mathrm{Chi}^{2}=3.47, \mathrm{df}=5(\mathrm{P}=0.63) ; \mathrm{I}^{2}=0 \% \\
\text { Test for overall effect: } Z=11.67(\mathrm{P}<0.00001)\end{array}$} \\
\hline Total $(95 \% \mathrm{Cl})$ & $100.0 \%$ & $7.48[5.64,9.94]$ \\
\hline $\begin{array}{l}\text { Total events } \\
\text { Heterogeneity: Tau }= \\
\text { Test for overall effect: }\end{array}$ & $\begin{array}{l}4, C n{ }^{2}= \\
13.93<F\end{array}$ & $\begin{array}{l}4.03, d f=12(P=0.30) ; I^{2}=14 \% \\
0.00001)\end{array}$ \\
\hline
\end{tabular}

Odds Ratio

Odds Ratio

M-H, Random, 95\% Cl

$7.4 \%-6.32[2.40,16.66]$

$11.6 \% \quad 4.94[2.36,10.36]$

$6.10[2.33,15.98]$

$26.83[7.50,95.96]$

$12.60[1.44,110.31]$

$6.47[2.76,15.19]$

$33.00[8.69,125.27]$

$8.81[5.18,15.00]$

Figure 2. Forest plot of correlation between STAT3/p-STAT3 expression level and breast cancer occurrence. Random-effects OR $=7.48,95 \% \mathrm{CI}=5.64-9.94, \mathrm{P}=0.30, \mathrm{I}^{2}=14 \%$.

using the random-effects model. STAT3/p-STAT3 expression level in breast cancer tissues was higher than that in normal ones $(\mathrm{OR}=7.48,95 \% \mathrm{CI}=5.64-9.94)$. In the subgroup analysis, we achieved a consistent result (STAT3: $\mathrm{OR}=8.81,95 \% \mathrm{CI}=5.18-15.00$; p-STAT3: $\mathrm{OR}=7.13,95 \% \mathrm{CI}=5.13-9.92)$. The results demonstrated that the STAT3/p-STAT3 expression level in breast cancer tissue was higher than that in normal ones (Fig. 2).

The correlation of STAT3/p-STAT3 expression level and histological differentiation. 13 studies reported the correlation of STAT3/p-STAT3 expression level and histological differentiation, with data inside being used to analyze the difference between low-differentiated and high-differentiated cases. In the 13 reports, 395 cases were high-differentiated and 750 were low-differentiated. There was no substantial heterogeneity in each group $\left(\mathrm{P}=0.25, \mathrm{I}^{2}=27 \%\right)$, and the random-effects model was chosen. The result showed that the STAT3/p-STAT3 expression level in high-differentiated cases was higher than that in low-differentiated cases $(\mathrm{OR}=2.13,95 \%$ $\mathrm{CI}=1.53-2.98)$. In the subgroup analysis, we achieved a consistent result (STAT3: $\mathrm{OR}=1.83,95 \% \mathrm{CI}=1.23-$ 2.72; p-STAT3: $\mathrm{OR}=2.34,95 \% \mathrm{CI}=1.18-4.67)$. The analytical results were stable, as shown in Fig. 3 .

The correlation of STAT3/p-STAT3 expression level and breast cancer TNM stages. $\quad 15$ studies reported the correlation of STAT3/p-STAT3 expression level and breast cancer TNM stages. We regarded stages I and II as early stage (involving 1271 cases), III and IV as late stage (involving 509 cases). We used the random-effects model and there was no evident heterogeneity inside $\left(\mathrm{P}=0.11, \mathrm{I}^{2}=32 \%\right)$. The results showed that the STAT3/p-STAT3 expression level in breast cancer of the late stage was much higher than the early stage $(\mathrm{OR}=3.58,95 \% \mathrm{CI}=2.44-5.25)$. In the subgroup analysis, we achieved a consistent result (STAT3: OR $=3.37,95 \% \mathrm{CI}=1.98-5.73$; $\mathrm{p}$-STAT3: $\mathrm{OR}=3.88,95 \% \mathrm{CI}=2.44-5.25)$, as shown in Fig. 4 .

The correlation of STAT3/p-STAT3 expression level and breast cancer lymphatic metastasis. 11 studies reported the correlation of STAT3/p-STAT3 expression level and breast cancer lymphatic metastasis, including 1249 patients of lymphatic metastasis and 350 patients of normal condition. The random-effects model was used and no evident heterogeneity inside $\left(\mathrm{P}=0.14, \mathrm{I}^{2}=32 \%\right)$. The results showed that the STAT3/p-STAT3 expression level of lymphatic metastasis patients is evidently higher than that for other patients $(\mathrm{OR}=3.72,95 \% \mathrm{CI}=2.59-5.35)$. In the subgroup analysis, we achieved a consistent result (STAT3: OR $=5.19,95 \% \mathrm{CI}=3.42-7.86$; p-STAT3: $\mathrm{OR}=2.69,95 \% \mathrm{CI}=1.63-4.43)$. The results are shown in Fig. 5.

Publication bias. Egger's test performed in STATA 14.0 and funnel plots performed in RevMan 5.3 were used to assess the publication bias of inclusive researches. 18 studies were taken into research, with the funnel plot being shown in Fig. 6, which indicated that there was no obvious publication bias in these studies. 


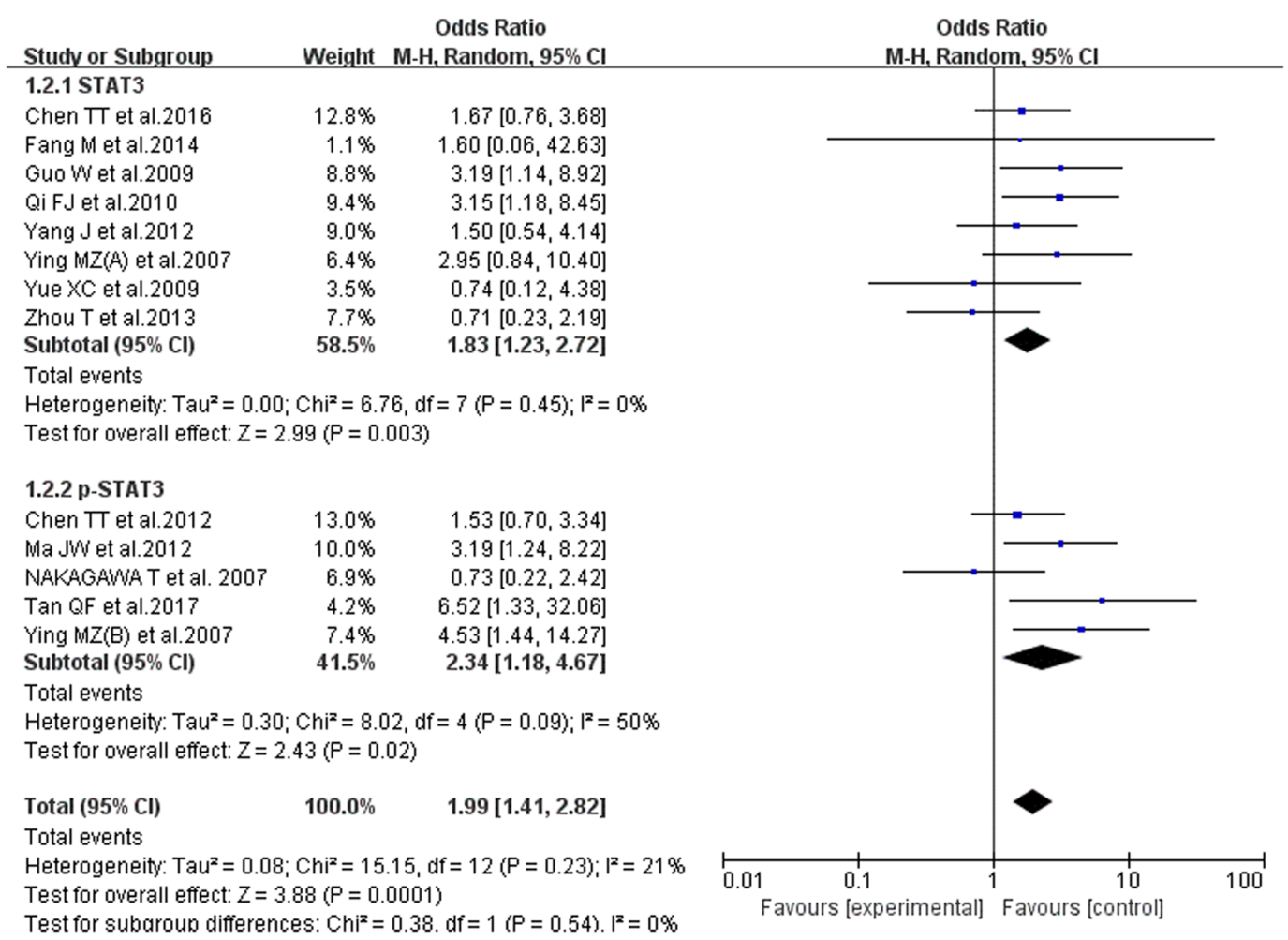

Odds Ratio

Odds Ratio

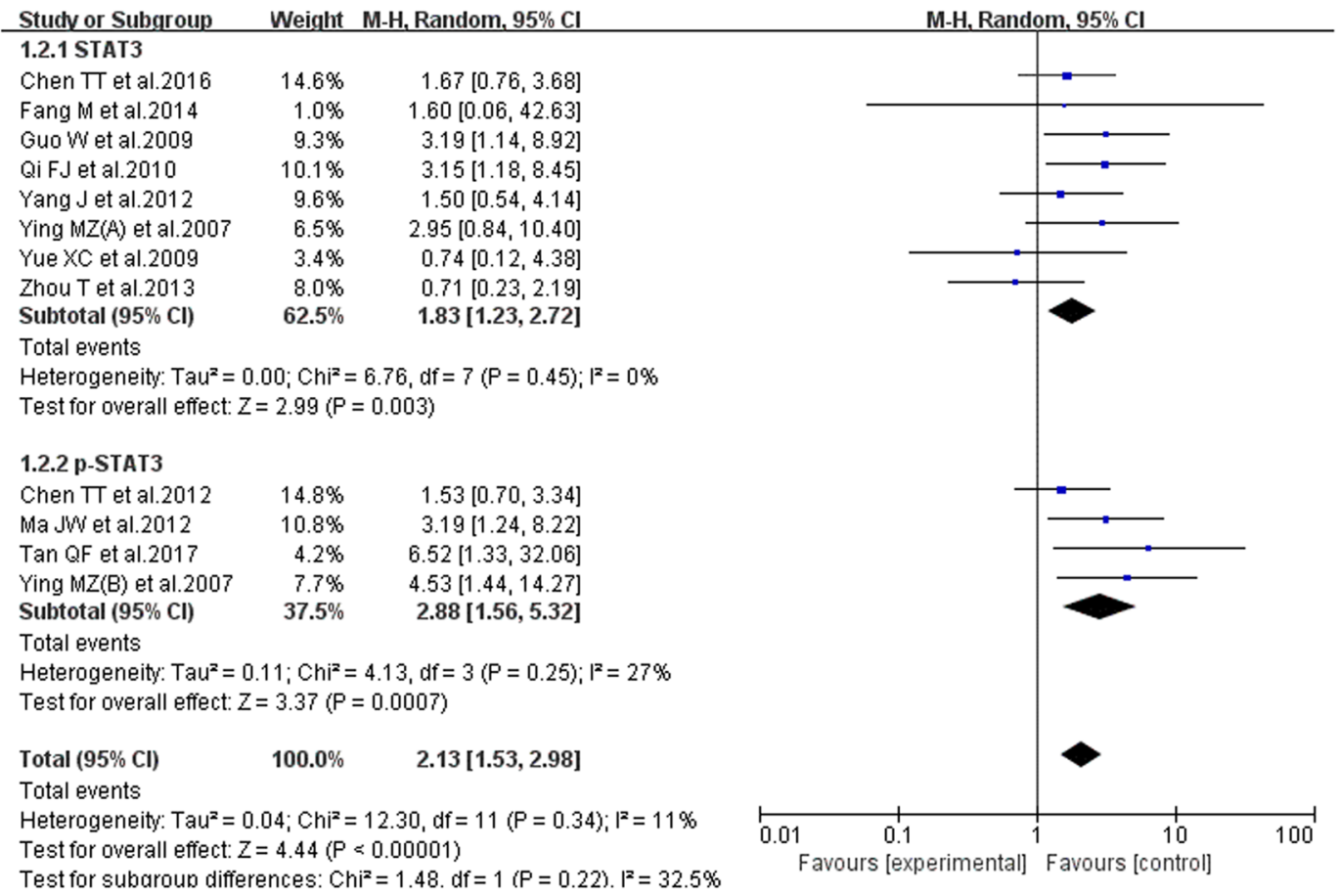

Figure 3. Forest plot of Correlation between STAT3/p-STAT3 expression level and histological differentiation. Random-effects $\mathrm{OR}=2.13,95 \% \mathrm{CI}=1.53-2.98, \mathrm{P}=0.25, \mathrm{I}^{2}=27 \%$.

STAT3/p-STAT3 expression and survival prognosis. To further study the relationship between STAT3 (or p-STAT3) expression and patients' survival prognosis, five studies were used.

Considering the studies on the relationship between STAT3/p-STAT3 and survival prognosis of breast cancer patients are rare, and the papers did not use a uniformed statistical method, it's very difficult to generate statistical graphs. The results were shown in the Table 3. 


\begin{tabular}{|l|l|l|l|l|}
\hline Reference & $\begin{array}{l}\text { Patient } \\
\text { numbers }\end{array}$ & $\begin{array}{l}\text { Follow- } \\
\text { up(years) }\end{array}$ & STAT3/p-STAT3 & outcome \\
\hline Li SJ et al. ${ }^{38}$ & 67 & 8 & STAT3 & $\begin{array}{l}\text { associated with } \\
\text { reduced OS }\end{array}$ \\
\hline Zhang N et al $^{41}$ & 91 & 13 & p-STAT3 & $\begin{array}{l}\text { no significant } \\
\text { correlation with OS }\end{array}$ \\
\hline Xu S et al. ${ }^{44}$ & 80 & 5 & STAT3 & $\begin{array}{l}\text { associated with } \\
\text { reduced OS }\end{array}$ \\
\hline Wang QT et al. ${ }^{50}$ & 130 & 10 & STAT3 & $\begin{array}{l}\text { associated with } \\
\text { reduced OS }\end{array}$ \\
\hline $\begin{array}{l}\text { Sheen-Chen } \text { et } \\
\text { al. }^{53}\end{array}$ & 102 & 5 & STAT3\& p-STAT3 & $\begin{array}{l}\text { associated with } \\
\text { reduced OS }\end{array}$ \\
\hline
\end{tabular}

Table 3. Studies on the prognostic of STAT3/p-STAT3 in breast cancer. p-STAT3: phosphorylated STAT3; OS: overall survival.

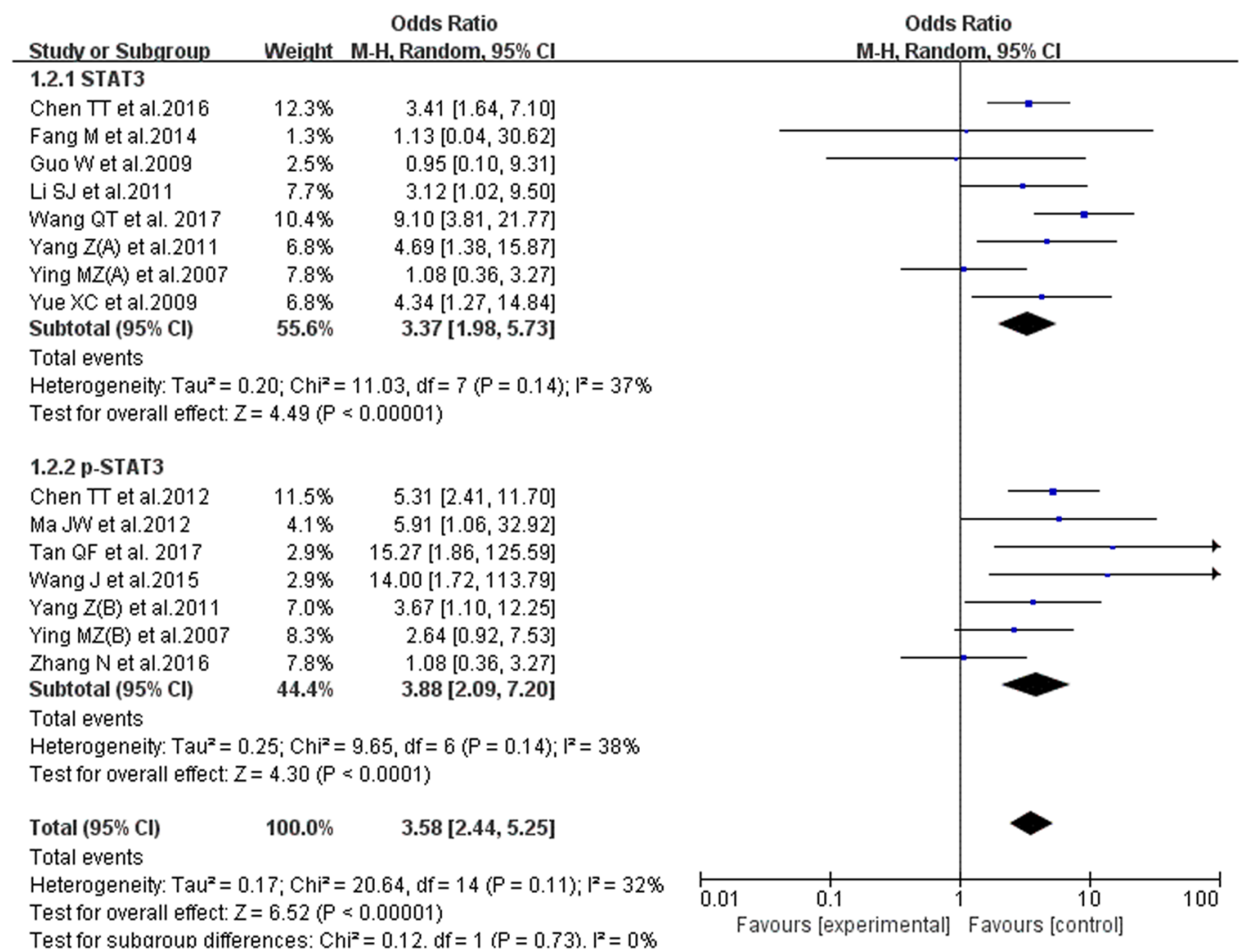

Figure 4. Forest plot of Correlation between STAT3/p-STAT3 expression level and breast cancer TNM stages. Random-effects $\mathrm{OR}=3.58,95 \% \mathrm{CI}=2.44-5.25, \mathrm{P}=0.11, \mathrm{I}^{2}=32 \%$.

\section{Discussion}

JAK-STAT signal pathway is of prime importance for STAT3 phosphorylation ${ }^{10}$. When receptors are stimulated by some special cytokines or growth factors, tyrosine kinase (JAKs) and Src tyrosine kinase coupled with these receptors would phosphorylate STAT3. Moreover, some environmental factors like smoke and UV radiation also phosphorylates STAT3 through tyrosine kinases like Src and ABL independently of receptors ${ }^{5}$.

The gene expression products controlled by STAT3 have multiple functions, like the growth and proliferation of cells, angiogenesis and immunosuppression. P-STAT3 could improve the occurrence of cancers by inducing different kinds of genes controlling cell proliferation to express abnormally. MYC ${ }^{11}$, cyclin D1/D2 ${ }^{12}, \mathrm{BCL}^{-\mathrm{XL}^{13}}$, $\mathrm{MCL}^{14}$, surviving ${ }^{15-17}$ and $\mathrm{p} 53^{18}$ gene expression could improve cell growth and proliferation; VEGF ${ }^{19,20}, \mathrm{HGF}^{21}$, $\mathrm{bFGF}^{22}, \mathrm{HIF} 1 \alpha^{23,24}, \mathrm{MMP}^{25}, \mathrm{MMP}^{26}$, IL-12 $2^{27-29}$, IFN $\beta^{27,30}$, IFN $\gamma^{31}, \mathrm{CXCL} 10^{30}, \mathrm{p} 53^{18}$ and AKT ${ }^{23}$ gene expression could improve angiogenesis; IL- $6^{28}$, IL- $10^{32,33}$, TGF $\beta^{32,34}$, VEGF $^{19,20}$, IFN $\beta^{27,30}$, IFN $\gamma^{31}$, IL-12 $2^{27,29}$, TNF $^{27,28}$, $\mathrm{CXCL}_{10}{ }^{27}, \mathrm{CCL}^{27}$, MHC class II ${ }^{27,31}, \mathrm{CD}^{27} 0^{27,31}$ and $\mathrm{CD}^{27} 6^{27,31}$ gene expression could induce immunosuppression.

Currently, abundant studies have reported that the STAT3 or p-STAT3 expression has close connection with the occurrence, differentiation, TNM stages and lymphatic metastasis of breast cancer. However, on the one hand, simplex research samples are scarce and have no statistical significance; on the other hand, the results of each research are different. So we performed this meta-analysis to search and screen researches which are satisfactory, and to make our analysis statistically significant. 
Odds Ratio

Odds Ratio

Study or Subgroup

Weight M-H. Random. $95 \% \mathrm{Cl}$

M-H. Random. 95\% C

\subsubsection{STAT3}

Chen TT et al.2016

$13.4 \%$

$4.03[1.96,8.30]$

Li S.J et al. 2011

$8.3 \%$

$4.07[1.41,11.78]$

Wang QT et al.2017

$10.4 \%$

$9.03[3.67,22.20]$

Yang $J$ et al. 2012

$9.4 \%$

$4.75[1.80,12.54]$

Zhou T et al. 2013

$6.7 \%$

$6.07[1.78,20.67]$

Subtotal $(95 \% \mathrm{CI})$

$48.3 \%$

$5.19[3.42,7.86]$

Total events

Heterogeneity: $\mathrm{Tau}^{2}=0.00 ; \mathrm{Chi}^{2}=2.22, \mathrm{df}=4(\mathrm{P}=0.69) ; \mathrm{I}^{2}=0 \%$

Test for overall effect: $Z=7.74$ ( $P<0.00001)$

2.1.2 p-STAT3

Ma. JWet al. 2012

Tan $Q F$ et al. 2017

Wang J et al. 2015

$10.5 \%$

$6.0 \%$

Ying $M Z(B)$ et al.2007

Zhang $N$ et al. 2016

Zhang Wet al.2008

Subtotal $(95 \% \mathrm{Cl})$

$10.8 \%$

$7.7 \%$

$10.8 \%$

$5.8 \%$

$51.7 \%$

$$
\begin{array}{r}
2.06[0.84,5.03] \\
6.77[1.82,25.17] \\
1.62[0.68,3.89] \\
6.04[1.98,18.48] \\
1.62[0.68,3.89] \\
3.77[0.98,14.44] \\
2.69[1.63,4.43]
\end{array}
$$

Heterogeneity: $\operatorname{Tau}^{2}=0.11 ; \mathrm{Chi}^{2}=7.01, \mathrm{df}=5(\mathrm{P}=0.22) ; \mathrm{I}^{2}=29 \%$

Test for overall effect: $Z=3.88(P=0.0001)$

Total $(95 \% \mathrm{Cl})$

$100.0 \%$

$3.72[2.59,5.35]$

Total events

Heterogeneity: $\mathrm{Tau}^{2}=0.12 ; \mathrm{Chi}^{2}=14.77, \mathrm{df}=10(P=0.14) ; \mathrm{I}^{2}=32 \%$

Test for overall effect: $Z=7.08$ ( $P<0.00001$ )

Test for subaroun differences: $\mathrm{Chi}^{2}=3.92 . \mathrm{df}=1(\mathrm{P}=0.05) . \mathrm{I}^{2}=74.5 \%$

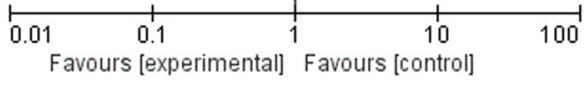

Figure 5. Forest plot of Correlation between STAT3/p-STAT3 expression level and breast cancer lymphatic metastasis. Random-effects $\mathrm{OR}=3.72,95 \% \mathrm{CI}=2.59-5.35, \mathrm{P}=0.14, \mathrm{I}^{2}=32 \%$.

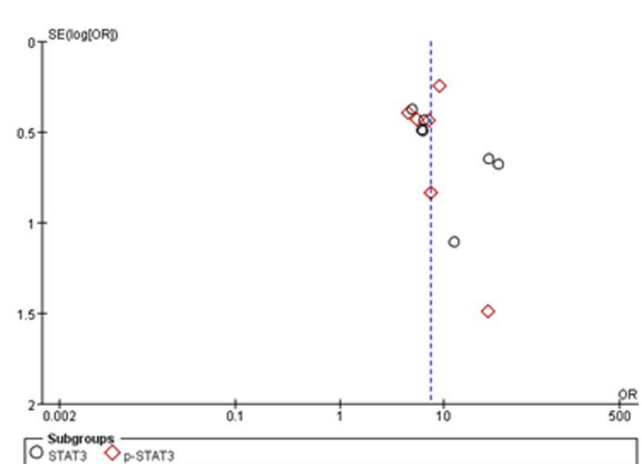

(a) Egger's test $\quad P=0.205$

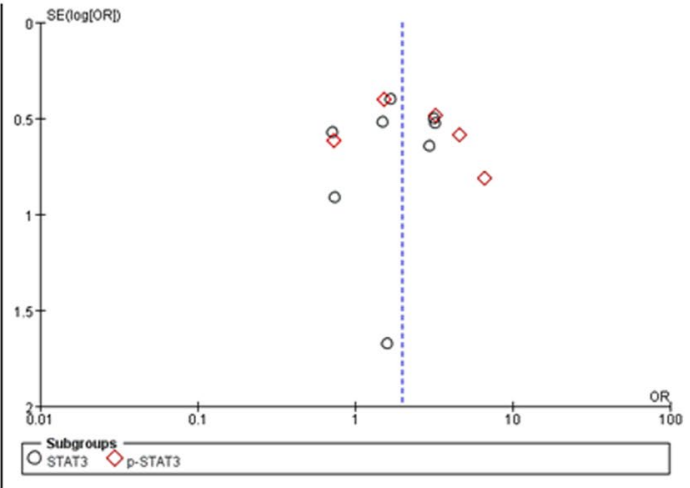

(b) Egger's test $=0.957$

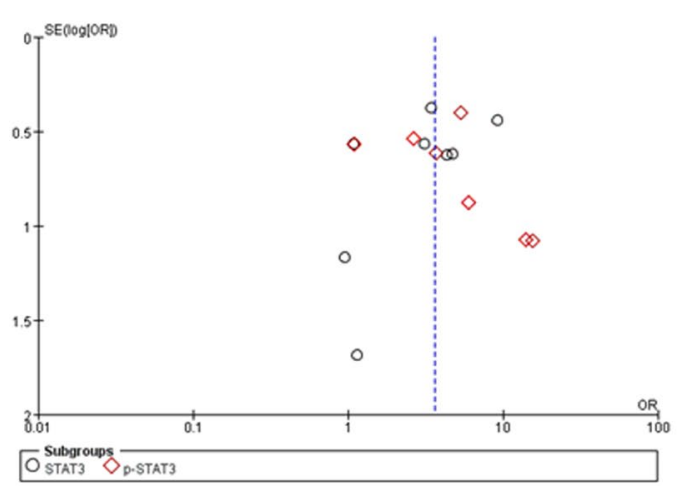

(c) Egger's test $\mathrm{P}=\mathbf{0 . 2 7 9}$

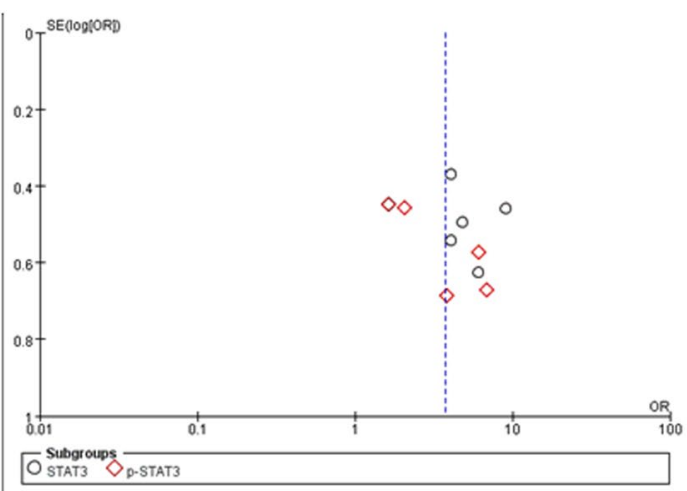

(d) Egger's test $\quad \mathrm{P}=\mathbf{0 . 2 9 0}$

Figure 6. Funnel plots and Egger's test for publication bias. (a) Breast cancer occurrence, (b) histological differentiation, (c) TNM stages, (d) lymphatic metastasis. 
The breast cancer patients in our research were Chinese. The results showed that STAT3 or p-STAT3 expression in breast cancer tissues was much higher than that in normal ones, indicating a positive correlation between STAT3 or p-STAT3 overexpression and the occurrence of breast cancer. In addition, our research found a higher STAT3 or p-STAT3 expression level in breast cancer cells which kept the characteristics of rapid proliferation, less differentiation and lymphatic metastasis. The STAT3 expression difference has not been found between patients of different ages or tumor sizes. Above all, STAT3/p-STAT3 expression could induce the occurrence of breast cancer; in breast cancer cells, STAT3 or p-STAT3 overexpression could also predict rapid proliferation, the late stage of TNM and the possibility of lymphatic metastasis.

As for survival the relationship between STAT3 (or p-STAT3) expression and patients' survival prognosis, the outcomes of five studies in Table 3 were not in full accord, but most studies showed the trend that the overexpression of STAT3 (or p-STAT3) was associated with reduced OS, indicating the expression of STAT3/p-STAT3 plays a prognostic role in Chinese breast cancer patients.

There are still many limitations to our analysis. First of all, the inclusive researches are mainly focused on the patients in China, with insufficient persuasion for more massive ethnic groups. Secondly, the difference of inclusive research quality could also affect the reliability of our analysis. Thirdly, the operation methods and evaluation criteria were different in inclusive researches, bringing the potential indeterminacy.

In conclusion, the occurrence of breast cancer has a close correlation with STAT3/p-STAT3 overexpression and phosphorylation. Also, the STAT3/p-STAT3 expression level in tumor tissue could indicate the deteriorating condition, meaning that STAT3/p-STAT3 could be an important target for various cancers. More studies remain to be undertaken for the target STAT3/p-STAT3 protein.

\section{References}

1. Luo, L. et al. Research progress in applying proteomics technology to explore early diagnosis biomarkers of breast cancer, lung cancer and ovarian cancer. Asian Pacific Journal of Cancer Prevention 15, 8529-8538 (2014).

2. Li, C. Y. et al. Clinicopathological significance and prognostic value of signal transducer and activator of transcription 3 (STAT3) and phospho-STAT3 expression in breast cancer: a meta-analysis of 4031 cases. International. Journal of Clinical and Experimental Medicine 9, 17295-17308 (2016).

3. Gough, D. J. et al. Mitochondrial STAT3 supports Ras-dependent oncogenic transformation. Science 324, 1713-1716 (2009).

4. Liu, Y. et al. Meta-analysis of STAT3 and phospho-STAT3 expression and survival of patients with breast cancer. Oncotarget 9 , 13060-13067 (2018).

5. Yu, H., Kortylewski, M. \& Pardoll, D. Crosstalk between cancer and immune cells: role of STAT3 in the tumour microenvironment. Nature Reviews Immunology 7, 41-51 (2007).

6. Yang, C. et al. Increased drug resistance in breast cancer by tumor-associated macrophages through IL-10/STAT3/bcl-2 signaling pathway. Medical Oncology 32, 352 (2015).

7. Tan, Q. et al. SrcSTAT3-dependent heme oxygenase-1 induction mediates chemoresistance of breast cancer cells to doxorubicin by promoting autophagy. Cancer Science 106, 1023-1032 (2015).

8. Chen, W. Q. \& Zheng, R. S. Incidence, mortality and survival analysis of breast cancer in China. Chinese. Journal of Clinical Oncology 42, 668-674 (2015).

9. Chen, W. Q. et al. Cancer Statistics in China, 2015. Ca A Cancer Journal for Clinicians 66, 115-132 (2016).

10. Yu, H., Pardoll, D. \& Jove, R. STATs in cancer inflammation and immunity: a leading role for STAT3. Nature Reviews Cancer 9 , 798-809 (2009)

11. Bowman, T. et al. STAT3-mediated Myc expression is required for Src transformation and PDGF-induced mitogenesis. Proceedings of the National Academy of Sciences of the United States of America 98, 7319-7324 (2001).

12. Sinibaldi, D. et al. Induction of p21WAF1/CIP1 and cyclin D1 expression by the Src oncoprotein in mouse fibroblasts: role of activated STAT3 signaling. Oncogene 19, 5419-5427 (2000).

13. Karni, R., Jove, R. \& Levitzki, A. Inhibition of pp60c-Src reduces Bcl-XL expression and reverses the transformed phenotype of cells overexpressing EGF and HER-2 receptors. Oncogene 18, 4654-4662 (1999).

14. Niu, G. et al. Roles of activated Src and STAT3 signaling in melanoma tumor cell growth. Oncogene 21, 7001-7010 (2002).

15. Aoki, Y., Feldman, G. M. \& Tosato, G. Inhibition of STAT3 signaling induces apoptosis and decreases survivin expression in primary effusion lymphoma. Blood 101, 1535-1542 (2003).

16. Amin, H. M. et al. Selective inhibition of STAT3 induces apoptosis and G1 cell cycle arrest in ALK-positive anaplastic large cell lymphoma. Oncogene 23, 5426-5434 (2004).

17. Gritsko, T. et al. Persistent activation of stat 3 signaling induces survivin gene expression and confers resistance to apoptosis in human breast cancer cells. Clinical Cancer Research 12, 11-19 (2006).

18. Niu, G. et al. Role of STAT3 in regulating p53 expression and function. Molecular and Cellular Biology 25, 7432-7440 (2005).

19. Niu, G. et al. Constitutive STAT3 activity up-regulates VEGF expression and tumor angiogenesis. Oncogene 21, 2000-2008 (2002).

20. Wei, D. et al. STAT3 activation regulates the expression of vascular endothelial growth factor and human pancreatic cancer angiogenesis and metastasis. Oncogene 22, 319-329 (2003).

21. Hung, W. \& Elliott, B. Co-operative effect of c-Src tyrosine kinase and STAT3 in activation of hepatocyte growth factor expression in mammary carcinoma cells. Journal of Biological Chemistry 276, 12395-12403 (2001).

22. Xie, T. X. et al. Activation of stat 3 in human melanoma promotes brain metastasis. Cancer Research 66, 3188-3196 (2006).

23. Xu, Q. et al. Targeting STAT3 blocks both HIF-1 and VEGF expression induced by multiple oncogenic growth signaling pathways. Oncogene 24, 5552-5560 (2005).

24. Jung, J. E. et al. STAT3 is a potential modulator of HIF-1-mediated VEGF expression in human renal carcinoma cells. FASEB Journal $19,1296-1298(2005)$

25. Xie, T. X. et al. STAT3 activation regulates the expression of matrix metalloproteinase-2 and tumor invasion and metastasis. Oncogene 23, 3550-3560 (2004).

26. Dechow, T. N. et al. Requirement of matrix metalloproteinase- 9 for the transformation of human mammary epithelial cells by STAT3-C. Proceedings of the National Academy of Sciences of the United States of America 101, 10602-10607 (2004).

27. Wang, T. et al. Regulation of the innate and adaptive immune responses by STAT3 signaling in tumor cells. Nature Medicine 10, 48-54 (2004).

28. Sumimoto, H., Imabayashi, F., Iwata, T. \& Kawakami, Y. The BRAF-MAPK signaling pathway is essential for cancer-immune evasion in human melanoma cells. Journal of Experimental Medicine 203, 1651-1656 (2006).

29. Hoentjen, F., Sartor, R. B., Ozaki, M. \& Jobin, C. STAT3 regulates NF- $\mathrm{BB}$ recruitment to the IL-12p40 promoter in dendritic cells. Blood 105, 689-696 (2005).

30. Burdelya, L. et al. STAT3 activity in melanoma cells affects migration of immune effector cells and nitric oxide-mediated antitumor effects. Journal of Immunology 174, 3925-3931 (2005). 
31. Kortylewski, M. et al. Inhibiting STAT3 signaling in the hematopoietic system elicits multicomponent antitumor immunity. Nature Medicine 11, 1314-1321 (2005).

32. Kinjyo, I. et al. Loss of SOCS3 in T helper cells resulted in reduced immune responses and hyperproduction of interleukin 10 and transforming growth factor- $\beta 1$. Journal of Experimental Medicine 203, 1021-1031 (2006).

33. Herbeuval, J. P., Lelievre, E., Lambert, C., Dy, M. \& Genin, C. Recruitment of STAT3 for production of IL-10 by colon carcinoma cells induced by macrophagederived IL-6. Journal of Immunology 172, 4630-4636 (2004).

34. Kasprzycka, M., Marzec, M., Liu, X., Zhang, Q. \& Wasik, M. A. Nucleophosmin/anaplastic lymphoma kinase (NPM/ALK) oncoprotein induces the T regulatory cell phenotype by activating STAT3. Proceedings of the National Academy of Sciences of the United States of America 103, 9964-9969 (2006).

35. Chen, T. T., Wang, Y. J., Yang, M. M., Pan, M. H. \& Meng, G. Expression of p-STAT 3 and SOCS 3 in human breast cancer. Chinese. Journal of Histochemistry and Cytochemistry 21, 295-299 (2012).

36. Fang, M. et al. Expressions and clinical significances of SMO, STAT3 and MMP-9 in triple negative breast cancer. Chinese. Journal of Immunology 30, 821-830 (2004).

37. Guo, W., Li, H. T. \& Zhang, M. L. Expression of STAT3 in breast cancer and its clinical significance. Journal of Bengbu Medical College 34, 890-892 (2009).

38. Li, S. J., Jia, H. Y., Han, B., Wu, D. \& Fu, T. Expression of STAT3 protein in human breast cancer tissue and its clinical significances. Journal of Jilin University (Medicine Edition) 37, 72-75 (2011).

39. Ma, J. W. et al. Expression and clinical significance of p-STAT3 VEGF Survivin in breast cancer. Ningxia Medical Journa 34, 1202-1204 (2012).

40. Qi, F. J., Zhao, S. P. \& Zhu, P. The expression and significance of STAT3 and CyclinD1 protien in breast cancer. Shandong Medical Journal 50, 106-108 (2010).

41. Zhang, N. et al. Human papillomavirus infection correlates with inflammatory Stat3 signaling activity and IL-17 expression in patients with breast cancer. American. Journal of Translational Research 8, 3214-3226 (2016).

42. Wang, J. et al. Clinical significance of phosphorylated signal transducer and activator of transcription 3 activing and interleukin-17 in patients with breast cancer. Acta Anatomica Sinica 46, 791-796 (2015).

43. Zhou, T. et al. Down-regulation of GRIM-19 is associated with STAT3 overexpression in breast carcinomas. Human Pathology 44, 1773-1779 (2013).

44. Xu, S. et al. Study of relationship between infection of human HPV and expression of STAT3. SOCS3 in breast cancer. Journal of Clinical and Experimental Medicine 15, 2205-2207 (2016).

45. Yang, J. et al. Expression and Clinical Signifiance of STAT-3 and Enolase-1 in Breast Cancer. Cancer Research on Prevention and Treatment 39, 1451-1455 (2012).

46. Yang, Z., Yan, L. \& Cai, J. H. Expression and clinical significance of STAT3 and pSTAT3 in tissues of breast cancer. Chinese Journal of Clinical Oncology and Rehabilitation 18, 24-27 (2011).

47. Ying, M. Z. et al. Expressions of signal transducer and activators of transcription 3 (STAT3) and suppressor of cytokine signaling 3 (SOCS3) proteins in breast carcinoma and their association with biological behaviors. Tumor 27, 298-302 (2007).

48. Yue, X. C. \& Li, D. Q. Expression of stat-3 and survivin in breast carcinoma and its significance. Journal of Beng bu Medical College 34, 584-587 (2009).

49. Zhang, W., Wang, Y. J., Xue, C. Y. \& Fu, Q. Relationship between expression of STAT3 phosphorylation and lymph node metastasis in breast cancer. Chinese Journal of Cancer Prevention and Treatment 15, 440-443 (2008).

50. Wang, Q. Q., Huang, H. Y., Zou, Q. F. \& Deng, Q. H. Expression level and clinical features of STAT3 in breast cancer. The Journal of Practical Medicine. 33, 1972-1975 (2017).

51. Tan, Q. F. et al. The expressions and correlation of p-STAT3 and twist in nospecial type of invasive ductal carcinoma of breast. Medical Science Journal of Central South China 45, 113-116 (2017).

52. Chen, T. T., Yang, F. \& Chen, X. H. Expression of STAT3 and miR-125a-5p in human breast cancer and their relationship. Chinese. Journal of Clinical and Experimental Pathology. 32, 971-974 (2016).

53. Sheen-Chen, S. M., Huang, C. C., Tang, R. P., Chou, F. F. \& Eng, H. L. Prognostic value of signal transducers and activators of transcription 3 in breast cancer. Cancer Epidemiol Biomarkers Prev 17, 2286-2290 (2008).

\section{Acknowledgements}

This research work was supported by National Natural Science Foundation of China (Grant No.81673298 and No. 81402791), Natural Science Foundation of the Jiangsu Higher Education Institutions of China for Excellent Young Talents (Grant No. BK20180077).

\section{Author Contributions}

Yang Li, Feng Chang, and Wenying Yu contributed to the planning, execution, and analysis of the study. Yue Wang, Zhixiang Shi, and Jianghan Liu contributed to the interpretation of data and completion of figures and tables. Shuyun Zheng, Jinsong Yang, Yi Liu and Yuhua Yang participated in the revision of the manuscript for submission. All the authors read and approved the final manuscript.

\section{Additional Information}

Competing Interests: The authors declare no competing interests.

Publisher's note: Springer Nature remains neutral with regard to jurisdictional claims in published maps and institutional affiliations.

(c) (i) Open Access This article is licensed under a Creative Commons Attribution 4.0 International

License, which permits use, sharing, adaptation, distribution and reproduction in any medium or format, as long as you give appropriate credit to the original author(s) and the source, provide a link to the Creative Commons license, and indicate if changes were made. The images or other third party material in this article are included in the article's Creative Commons license, unless indicated otherwise in a credit line to the material. If material is not included in the article's Creative Commons license and your intended use is not permitted by statutory regulation or exceeds the permitted use, you will need to obtain permission directly from the copyright holder. To view a copy of this license, visit http://creativecommons.org/licenses/by/4.0/.

(c) The Author(s) 2019 